Clarke, R. T. J. (1959). J. gen. Microbiol. 20, 549-553

\title{
A Dextran-Fermenting Organism from the Rumen Closely Resembling Lactobacillus bifidus
}

\author{
BY R. T. J. CLARKE \\ Plant Chemistry Division, Department of Scientific and Industrial Research, \\ Palmerston North, New Zealand
}

\begin{abstract}
SUMMARY: An organism which ferments the dextran of Streptococcus bovis was isolated from the rumen of cows on a diet of fresh clover. The bacterium is a strictly anaerobic Gram-positive, non-sporing, branching rod that closely resembles Lactobacillus bifidus. It is of interest from the point of view of the metabolism of dextran in the rumen.
\end{abstract}

Hungate, Fletcher, Dougherty \& Barrentine (1955) stated that bacterial slime production in the rumen 'may be associated in an important way with bloat in ruminants'. Bailey \& Oxford (1958) showed that dextran is responsible for the greatly increased viscosity of sucrose-containing liquid cultures of rumen strains of Streptococcus bovis, and suggested that dextran slimes may be produced by $S$. bovis in the rumen of cows on a sucrose-containing ration such as spring grass or clover. As no dextran appears to accumulate in the rumen (R. W. Bailey, private communication) it is possible that it is broken down by microbial action. The isolations reported in this paper were made while searching for rumen organisms capable of attacking $S$. bovis dextran.

\section{METHODS}

Isolation of organism. Rumen contents were removed from fistulated cows and strained through gauze. Serial dilutions of the rumen liquor were made in dextran medium containing $(\%, \mathrm{w} / \mathrm{v})$ : Bacto-Tryptose, 1.0; Bacto-Yeast extract, 0.03; Streptococcus bovis dextran (Bailey \& Oxford, 1958), 0.15; Davis N.Z. agar, 1.1. The medium was kept at $45^{\circ}$ in $1 \mathrm{oz}$. bottles. Rumen liquor (1 ml.) was added to the first bottle, thoroughly mixed and $1 \mathrm{ml}$. transferred aseptically to the second bottle and so on for nine dilutions. The contents of each bottle were transferred aseptically to sterile tubes closed at one end with a rubber stopper. The open end was sealed with a $1: 1(\mathrm{v} / \mathrm{v})$ mixture of paraffin wax and petroleum jelly, and the tubes incubated at $37^{\circ}$ for $72 \mathrm{hr}$. The number of colonies present in the lowest dilution was noted. The agar was expelled and colonies picked out for plating on to dextran medium. The plates were incubated in a McIntosh \& Fildes jar in an atmosphere of $95 \%(\mathrm{v} / \mathrm{v}) \mathrm{H}_{2}+5 \%(\mathrm{v} / \mathrm{v}) \mathrm{CO}_{2}$. Subcultivation was continued until the cultures were considered to be pure.

Faeces were inoculated into the tomato juice broth of Rogosa et al. (1953) and incubated in an atmosphere of $95 \%(\mathrm{v} / \mathrm{v}) \mathrm{H}_{2}+5 \%(\mathrm{v} / \mathrm{v}) \mathrm{CO}_{2}$ at $37^{\circ}$ for $48 \mathrm{hr}$. Plates containing tomato juice broth solidified with $1 \cdot 1 \%(\mathrm{w} / \mathrm{v})$ agar were inoculated and incubated for $48 \mathrm{hr}$. 
Cultures were maintained by frequent transfer in tomato juice medium with occasional passage through media containing dextran.

Identification of organism. The methods followed those of Rogosa et al. (1953). Fermentation tests were carried out in duplicate with washed suspensions from $48 \mathrm{hr}$. tomato juice cultures as inocula. Nitrate reduction was tested in ox heart infusion broth containing $(\%, \mathrm{w} / \mathrm{v}): \mathrm{KNO}_{3}, \mathbf{0} \cdot \mathbf{1}$; BactoYeast extract, $\mathbf{0 \cdot 3}$ (Costilow \& Humphreys, 1955).

Lactic acid was determined by the method of Barker \& Summerson (1941) and, together with the lower fatty acids, by partition chromatography on Celite with chloroform/butanol solvents (Swim \& Krampitz, 1954).

\section{RESULTS}

Characters of organism isolated. Two strains were isolated from the rumen; strain D 13/293 from cow no. 293 on a diet of fresh red clover, and strain D15/1 from cow no. 1 on a diet of fresh clover and clover hay. Strains D 13/293 and D 15/1 were present in the rumen at a concentration of $2 \times 10^{7}$ and $7 \times 10^{4}$ organisms $/ \mathrm{ml}$. rumen contents, respectively.

In liquid culture the organisms were slender, sometimes pleomorphic rods, $0.4-0.8 \mu \times 2-8 \mu$, occurring singly and in clumps; chain formation was not evident; Gram positive, but tending to stain irregularly in old cultures; nonmotile. On solid media there was a large number of irregular, club, branched and $Y$-forms. Colonies on tomato juice agar and dextran agar plates were 0.5-2 mm. diameter, circular, convex, entire, smooth, white and opaque. Liquid cultures were turbid within 1-2 days, clearing with a flocculent sediment. Strictly anaerobic conditions were essential for growth; growth was better under $95 \%(\mathrm{v} / \mathrm{v}) \mathrm{H}_{2}+5 \%(\mathrm{v} / \mathrm{v}) \mathrm{CO}_{2}$ than under $100 \% \mathrm{H}_{2}$. Over a period of 6 months no increase in tolerance to oxygen or change from the typical 'bifid' form was noticed.

The organisms were catalase negative, reduced nitrate to nitrite, did not liquefy gelatin and did not coagulate milk. The lactic acid formed from glucose was optically inactive. A 40-50\% yield of volatile acid was produced from glucose in $72 \mathrm{hr}$. Gas production was not observed in the stab cultures of Rogosa et al. (1953).

The following carbohydrates were fermented in $48 \mathrm{hr}$. with the production of an acid $\mathrm{pH}$ value (numerical value in brackets): glucose $(4 \cdot 9)$, lactose (5.1), sucrose $(5 \cdot 1)$, fructose $(4 \cdot 9)$, maltose $(5 \cdot 3)$, xylose $(5 \cdot 6)$, arabinose (5.3), rhamnose $(5 \cdot 5)$, galactose $(5 \cdot 7)$, raffinose $(5 \cdot 3)$, cellobiose $(5 \cdot 2)$, starch $(5 \cdot 6)$, Streptococcus bovis dextran (5·2).

The following compounds were not fermented: inositol, mannose, mannitol, dulcitol, glycerol.

Growth of the organisms on dextran. The organisms grew profusely on a medium containing dextran as carbon source, producing lactic, formic and acetic acids. The enzyme responsible for the breakdown of the dextran was extracellular. It was obtained in a cell-free state and shown by paper chromatography to break the dextran molecule, characteristically, into tri-, tetra-, 
penta- and higher saccharides, a property useful for the identification of dextran. The properties of the enzyme are described elsewhere (Bailey \& Clarke, 1959).

Comparison with strains of Lactobacillus bifidus. As the organisms appeared similar to $L$. bifidus, four strains of $L$. bifidus were obtained for comparison; strains $\mathrm{D} 17 / \mathrm{H}, \mathrm{D} 18 / \mathrm{H}$ and $\mathrm{D} 21 / \mathrm{H}$ from the faeces of nursing infants (a traditional source of $L$. bifidus) and strain $\mathrm{D} 22 / \mathrm{T}$ from the faeces of a turkey.

All four strains of Lactobacillus bifidus were identical in morphology with the rumen organisms, exhibiting irregular, club, branched and Y-forms. All were obligate anaerobes and required $\mathrm{CO}_{2}$ for growth. As with the two rumen organisms, no increased tolerance to oxygen or change to unbranched forms took place with continued sub-culture.

Strain D17/H was also similar in other respects to the rumen strains; fermentation reactions were the same, and the organism utilized dextran and reduced nitrates to nitrites. Strains D18/H, D21/H (human) and D22/T (turkey) did not attack dextran or reduce nitrates and did not ferment xylose, arabinose, rhamnose, cellobiose and starch, all of which were fermented by the two rumen organisms and by Lactobacillus bifidus, D 17/H.

A strain labelled Lactobacillus bifidus (NCIB 2797) was also obtained from the National Collection of Industrial Bacteria, Teddington, Middlesex. This organism was an unbranched micro-aerophilic rod resembling $L$. brevis. Glucose, maltose, fructose, xylose, arabinose and galactose were fermented, the fermentations of the pentoses being particularly vigorous. The organism also reduced nitrates to nitrites.

\section{DISCUSSION}

Two types of Lactobacillus bifidus have been isolated in past years. Tissier (1900) first described the organism ('Bacillus bifidus') from the faeces of breast-fed infants. The organisms were Gram-positive straight or curved rods, some exhibiting a split or bifid structure. On repeated subculture the organism lost its bifid appearance and became an unbranched rod. Eggerth (1935) and Orla-Jensen, Orla-Jensen \& Winther (1936) described a second type of L. bifidus (Bacteroides bifidus; Bacterium bifidum) from the stools of adults. This organism maintained its bifid structure on subculture. Weiss \& Rettger $(1934,1938)$ proposed that the two types should be classified as L. bifidus type I, and $L$. bifidus type II. Type I, first isolated by Tissier, usually becomes unbranched and a facultative anaerobe, while Type II, first isolated from adult faeces by Eggerth \& Orla-Jensen, remains bifid and anaerobic. Much of the confusion still remaining was removed by Norris, Flanders, Tomarelli \& György (1950). These authors cultivated $L$. bifidus indefinitely in a bifid phase and discussed differences between the bifid organisms and unbranched bacilli which corresponded with $L$. bifidus Type II and $L$. bifidus Type I, as described by Weiss \& Rettger.

The two rumen organisms and the four strains of Lactobacillus bifidus described here correspond morphologically to L. bifidus type II of Weiss \& 
Rettger (1934, 1938). It should be noted that the rumen organisms produce optically inactive lactic acid from glucose, while the Type II strains (Weiss \& Rettger) of Orla Jensen produce optically active acid. The optical activity of the lactic acid produced by the faecal strains was not tested. In spite of their morphological similarity, the rumen organisms and the $L$. bifidus strains are divisible into two groups. The restricted fermentation ability of $L$. bifidus strains $\mathrm{D} 18 / \mathrm{H}, \mathrm{D} 21 / \mathrm{H}$ and $\mathrm{D} 22 / \mathrm{T}$, and their inability to reduce nitrates and to attack dextran distinguishes them from $L$. bifidus $\mathrm{D} 17 / \mathrm{H}$ and rumen organisms D13/293 and D15/1. The fermentation range of both groups is within that listed for L. bifidus (Tissier, 1900) in Bergey's Manual (1957).

It is generally accepted that members of the genus Lactobacillus, with the exception of strains of $L$. plantarum, are unable to reduce nitrates. Costilow \& Humphreys (1955) found that 18 of 38 strains of $L$. plantarum tested were able to reduce nitrates, and that nitrate reduction by some strains was enhanced by a decreased oxygen tension and by the addition of yeast extract to the medium. It is therefore not surprising that some strains of $L$. bifidus should reduce nitrates when grown anaerobically in the presence of yeast extract.

The only previous isolations of rumen organisms resembling Lactobacillus bifidus were made by Wasserman, Seeley \& Loosli (1953). These authors isolated organisms, which they suggested were variants of $L$. bifidus, from dilutions of rumen contents higher than $\mathbf{1 0}^{-6}$. The organisms were catalase negative and homofermentative, producing optically inactive lactic acid from glucose. It was suggested that these variants of $L$. bifidus ' may be important converters of non-protein nitrogen to protein nitrogen in the rumen'. No study was made of their action on dextran.

This is the first occasion on which a member of the genus Lactobacillus has been shown to ferment dextran, and the second occasion on which extracellular dextranases have been reported in bacteria. Hehre \& Sery (1952) demonstrated the formation of dextranases in members of the genus Bacteroides. The action of the enzyme preparations from these organisms produced glucose from dextran. Tsuchiya, Jeanes, Bricker \& Wilham (1952) tested 200 species of bacteria and yeasts for dextranase activity with negative results. Unfortunately these authors did not list the species tested. Bailey \& Clarke (1959) could not find any dextranase activity in single strains of four species of Lactobacillus other than $L$. bifidus.

The presence of dextran-attacking organisms in the rumen is to be expected when one considers the possible in vivo production of dextran by Streptococcus bovis. Dextran-attacking organisms could not be demonstrated in rumen contents during the winter when the cows were on a low sucrose diet. From these results it appears that L. bifidus is an important member of the rumen microflora only under certain conditions.

The author wishes to thank Dr A. E. Oxford for his helpful advice and criticism, and Miss C. E. Arbon for technical assistance. 


\section{REFERENCES}

Bailey, R. W. \& Clarke, R. T. J. (1959). A bacterial dextranase. Biochem. J. (in the Press).

Balley, R. W. \& Oxford, A. E. (1958). A quantitative study of the production of dextran from sucrose by rumen strains of Streptococcus bovis. J. gen. Microbiol. $19,130$.

Barken, S. B. \& Summerson, W. H. (1941). The colorimetric determination of lactic acid in biological material. J. biol. Chem. 138, 535.

Bergey's Manual of Determinative Bacteriology (1957). 7th ed. Ed. by Breed, R. S., Murray, E. G. D. \& Smith, N. R. Baltimore, Md. U.S.A.: Williams and Wilkins.

Costilow, R. N. \& Humphreys, T. W. (1955). Nitrate reduction by certain strains of Lactobacillus plantarum. Science, 121, 168.

EgGerth, A. H. (1935). The Gram-positive non-spore-bearing anaerobic bacilli of human faeces. J. Bact. 30, 277.

Hehre, E. J. \& Sery, T. W. (1952). Dextran-splitting anaerobic bacteria from the human intestine. J. Bact. 63, 424.

Hungate, R. E., Fletcher, D. W., Dougherty, R. W. \& Barrentine, B. F. (1955). Microbial activity in the bovine rumen: its measurement and relation to bloat. Appl. Microbiol. 3, 161.

Norris, R. F., Flanders, F., Tomarelui, R. M. \& György, P. (1950). The isolation and cultivation of Lactobacillus bifidus: a comparison of branched and unbranched strains. J. Bact. 60, 681 .

Orla-Jensen, S., Orla-Jensen, A. D. \& Winther, O. (1936). Bacterium bifidum and Thermobacterium intestinale. Zbl. Bakt. (Abt. II), 93, 321.

Rogosa, M., Wiseman, R. F., Mitchell, J. A., Disraely, M. N. \& Beaman, A. J. (1953). Species differentiation of oral lactobacilli from man including descriptions of Lactobacillus salivarius, nov spec \& Lactobacillus cellobiosus nov spec. J. Bact. 65, 681.

Swim, H. E. \& Krampitz, L. O. (1954). Acetic acid oxidation by Escherichia coli: evidence for the occurrence of a tricarboxylic acid cycle. J. Bact. 67, 419 .

Tissier, H. (1900). Recherches sur la flore intestinale des nourrissons. Thèse, Faculté de Medicine de Paris, Paris. Cited: Norris et al. (1950).

Tsuchiya, H. M., Jeanes, A., Bricker, H. M. \& Wilham, C. A. (1952). Dextrandegrading enzymes from moulds. J. Bact. 64, 513.

Wasserman, R. H., Seelex, H. W. \& Loosli, J. K. (1953). The physiology and nutrition of a rumen Lactobacillus. J. Anim. Sci. 12, 935.

Weiss, J. E. \& ReTtGer, L. F. (1934). Lactobacillus bifidus. J. Bact. 28, 501.

Weiss, J. E. \& Rettger, L. F. (1938). Taxonomic relationships of Lactobacillus bifidus (B. bifidus Tissier) and Bacteroides bifidus. J. infect. Dis. 62, 115. 